\title{
Demographic and socioeconomic inequalities in oral healthcare utilisation in Malaysia: evidence from a national survey
}

\author{
Yeung R'ong Tan ${ }^{1 *}$, Ee Hong Tan ${ }^{1}$, Suhana Jawahir ${ }^{1}$, Ainul Nadziha Mohd Hanafiah ${ }^{1}$
} and Muhammad Hafiz Mohd Yunos²

\begin{abstract}
Background: Throughout the years, oral healthcare utilisation in Malaysia has been low despite various efforts by the Ministry of Health Malaysia for improvement. This study aimed to determine the prevalence of oral healthcare utilisation and identify factors associated with oral healthcare utilisation among adults in Malaysia.

Methods: Secondary data analysis of adults aged 18 years and over from the National Health and Morbidity Survey 2019 was conducted in this study. Characteristics of respondents and those who utilised oral healthcare were described using complex sample descriptive statistics. Logistic regression analysis was performed to examine the association between the dependent and independent variables. Dependent variable was oral healthcare utilisation in the last 12 months. Independent variables were demographic and socioeconomic factors (predisposing, enabling and need characteristics) based on Andersen's Behavioural Model.

Results: A total of 11,308 respondents, estimated to represent 21.7 million adults aged 18 years and over in Malaysia were included in the analysis. Prevalence of oral healthcare utilisation in the last 12 months was 13.2\%. Demographic factors of sex, age, marital status, and socioeconomic factors of education level and occupation as well as health belief such as medical check-up were significantly related to oral healthcare utilisation. Enabling factor of household income quintile had significant association with oral healthcare utilisation. Inequalities were observed; females $(\mathrm{OR}=1.57$, $95 \% \mathrm{Cl}=1.25,1.96)$, younger adults $(\mathrm{OR}=1.64,95 \% \mathrm{Cl}=1.15,2.33)$, those who were married $(\mathrm{OR}=1.65,95 \% \mathrm{Cl}=1.23$, 2.22), those with higher education $(\mathrm{OR}=2.21,95 \% \mathrm{Cl}=1.23,3.99)$, those who had medical check-up in the last 12 months $(\mathrm{OR}=1.86,95 \% \mathrm{Cl}=1.53,2.25)$ and those with higher income $(\mathrm{OR}=1.43,95 \% \mathrm{Cl}=1.04,1.96)$ were more likely to utilise oral healthcare.

Conclusion: Understanding factors associated with utilisation of oral healthcare could help in formulating effective interventions to improve oral healthcare utilisation. Demographic and socioeconomic factors are strong determinants of oral healthcare utilisation in Malaysia. Appropriate interventions to strengthen the existing programmes aimed to promote regular and timely oral health check-ups are needed to improve oral healthcare utilisation.
\end{abstract}

Keywords: Oral health, Dental care, Adult, Socioeconomic factors, Healthcare inequalities, Malaysia

\footnotetext{
*Correspondence: dr.tanyr@moh.gov.my

${ }^{1}$ Institute for Health Systems Research, National Institutes of Health, Ministry of Health Malaysia, Blok B2, Kompleks NIH, No. 1, Jalan Setia Murni U13/52, Seksyen U13 Setia Alam, 40170 Shah Alam, Selangor, Malaysia

Full list of author information is available at the end of the article
}

\section{Background}

Oral diseases share common risk factors with noncommunicable diseases [1], affecting people throughout their lifetime and pose health burden for many countries. Untreated dental caries remain the most common health condition, while severe periodontal disease affects almost 
$10 \%$ of the global population, often resulting in tooth loss [2]. According to the National Oral Health Survey of Adults 2010, 88.9\% of adults in Malaysia had dental caries which included treated and untreated dental caries, and 94\% had periodontal conditions [3]. Assessment of treatment needs found that $54.1 \%$ of adults required treatment for dental caries and $87.2 \%$ required periodontal treatment [3]. The same study also indicated that almost everyone (98.3\%) needed oral healthcare in the past year but less than one-third of adults utilised oral healthcare services in the past one year [3].

Most oral diseases are preventable and can be treated in their early stages [4]. Regular oral healthcare utilisation is important for prevention and early detection of oral diseases to maintain good general well-being. Thomson et al. [5] indicated better self-reported oral health, less tooth loss and dental caries, and cleaner teeth in routine attendees than problem-oriented attendees of oral healthcare.

Oral healthcare in Malaysia is dichotomous, with a public sector which provides universal healthcare through the Ministry of Health Malaysia and a co-existing private sector. Malaysia is one of the early achievers of universal health coverage [6] through the provision of comprehensive public healthcare services funded by general taxation. Performance monitoring of the Sustainable Development Goals and Universal Health Coverage (UHC) shows Malaysia scores a UHC service coverage index of 73 out of 100 , which is higher than the average of the middle-income countries (64.9) [7]. This achievement is also higher than neighbouring ASEAN countries, except Singapore, Brunei, Thailand, and Vietnam (with scores ranged from 75 to 86) [7]. In Malaysia, oral healthcare is largely subsidised in the public sector where basic oral healthcare is accessible to all citizens with a nominal fee or for free, while the private sector renders services to all through fee-for-service. Preschool children, schoolchildren seventeen years and below, antenatal mothers, civil servants and the physically, mentally, and economically disadvantaged groups are entitled to free basic oral healthcare [8]. In the purview of oral healthcare for children, many lie under the public sector through the Incremental School Oral Health Programme, while adult oral healthcare lies under the public and private sectors [8]. There is no national health insurance scheme in place but third party payment schemes are available, albeit very few [8].

Many studies worldwide have addressed the frequency and determinants of oral healthcare utilisation [9-12]. Age, sex, urbanity, education level, income level, employment, and health status among others have been associated with oral healthcare utilisation in many studies around the world [9-12]. However, published research on associated factors of oral healthcare utilisation in Malaysia is scarce. Demographics, socioeconomic backgrounds, and beliefs differ in different parts of the world which influences oral healthcare utilisation differently [13-15]. Understanding the associated factors of oral healthcare utilisation helps to fill knowledge gaps regarding demographic and socioeconomic inequalities which are essential for health system strengthening [16] and better planning of oral healthcare services.

Many theoretical models have attempted healthcare utilisation explanation; Dutton Model [17], Evans and Stoddart Model [18], Health Belief Model [19], Grossman Model of Health Demand [20], and Andersen's Behavioural Model [21]. In our study, we adopted the Andersen's Behavioural Model which includes predisposing factors such as demographic profile and socioeconomic status, as well as enabling and need factors at the individual level to conceptualise factors that influence access and utilisation. Besides its ease of implementation, Andersen's Behavioural Model was chosen due to its popularity in modelling studies involving healthcare utilisation and accessibility [22].

In this study, we aimed to determine the prevalence of oral healthcare utilisation and use Andersen's Behavioural Model to identify the associated factors of oral healthcare utilisation by adults in Malaysia.

\section{Methods}

Study design and sampling

A secondary data analysis was performed using subset of adults aged 18 years and over from the National Health and Morbidity Survey (NHMS) 2019.

\section{Source of data}

NHMS 2019 was a cross-sectional, national household survey that targeted all non-institutionalised population who were residing in Malaysia for at least two weeks prior to data collection. Two-stage proportionate to size cluster sampling design was used to ensure national representativeness. All thirteen states and three Federal Territories were included, and stratification was performed by states and urban or rural localities. Primary stratum was states and Federal Territories, while secondary stratum was urban and rural strata formed within the primary stratum. First stage sampling involved random selection of all Enumeration Blocks (EBs) in Malaysia through probability proportional to size sampling technique. A total of $463 \mathrm{EBs}$ were selected as primary sampling units, $350 \mathrm{EBs}$ from the urban areas and $113 \mathrm{EBs}$ from the rural areas. Second stage sampling involved random selection of Living Quarters (LQs) from the selected EBs. Fourteen LQs were randomly selected from each selected EB. Department of Statistics Malaysia performed 
the random selection of EBs and LQs. All households within the selected LQs and all eligible respondents in the households were included in the study. Of the 5,791 eligible LQs, a total of 5,365 LQs were successfully interviewed giving a LQ response rate of 92.6\%. Respondents eligible for the survey were 18,546. A total of 16,688 respondents were successfully interviewed, giving an individual response rate of $90.0 \%$. The overall response rate for this community-based survey is therefore $83.4 \%$. A detailed methodology and sampling design of the survey is described in the NHMS 2019 official report [23].

\section{Data collection}

Data collection was conducted from July to October 2019 by trained data enumerators via face-to-face interview using bilingual (Malay and English), structured and validated questionnaire [24]. The questionnaire was programmed into an application and uploaded onto tablets as data collection tools. Data collected were stored and backed-up in Secure Digital (SD) cards, and subsequently uploaded to a central system after quality check. Eligible residents from the selected households were invited to participate in the survey. Vacant or closed houses during the first visit were revisited at least three times to ensure required sample size was achieved. Throughout the conduct of the study, the tenets of the Declaration of Helsinki was followed. Written informed consent was obtained from all participants prior to the interviews. The Medical Research and Ethics Committee (MREC), Ministry of Health Malaysia granted the permission to carry out the National Health and Morbidity Survey 2019 (NMRR-18-3085-44207).

\section{Data analysis}

Only respondents with complete data on all variables were included in the analysis, as the proportion of missing data was $3.14 \%(n=366)$. Complete case analysis may be used as primary analysis if the missing data proportion is below 5\% [25]. Analysis of all respondents including those with missing data in any variable included in the study was conducted beforehand, and produced the same results.

\section{Oral healthcare utilisation}

Oral healthcare utilisation (dependent variable) refers to oral healthcare utilisation by the respondents in the last 12 months prior to the interview. Oral healthcare utilisation was then assessed in relation to the potential determinants (independent variables).

\section{Potential determinants}

Predisposing factors include demographic profiles, socioeconomic status, and health belief of the respondents. Variables on the demographic profiles included sex, age, ethnicity, citizenship, and marital status. For socioeconomic status, education level, occupation, and working status were included. Utilisation of medical check-up were included under health belief where respondents were asked to answer "yes" or "no" to the question "In the last 12 months, did you go for medical check-up such as blood/urine tests/x-ray?".

Enabling factors include household income quintile and urbanity (rural-urban location). Urbanity was included as enabling factor [22] because urban areas have higher density of oral healthcare practitioners and oral healthcare facilities [8].

For need factor, self-rated health status was included, and respondents were asked to answer using a fivepoint scale (excellent, good, fair, poor, very poor) to the question "How would you rate your health status?". The responses were then grouped into three categories: (1) good to excellent health; (2) fair health; and (3) poor to very poor health, during data analysis.

Descriptive statistics were used to describe characteristics of respondents and those who utilised oral healthcare. Pearson's Chi-square tests with 95\% confidence intervals (CI) were used to compare the characteristics of respondents who used oral healthcare. Statistical significance was set at 0.05 .

\section{Logistics analysis}

Univariate analysis was performed to examine the association between independent variables (predisposing, enabling and need factors), and oral healthcare utilisation. Crude odds ratios (OR) were used to estimate strength of association between independent and dependent variables. Variables with $p$ value $<0.25$ [26] in univariate analysis were included in the multivariate regression analysis. Multivariate logistic regression model was fitted to determine the associated factors of oral healthcare utilisation. Adjusted OR with $95 \%$ confidence interval were determined. A $p$-value of $<0.05$ was considered statistically significant. The goodness of fit model was tested using Hosmer-Lemeshow statistics, and $p$-value $>0.05$ was considered as good fit.

All analyses used complex sample descriptive statistics to account for sample weightage and study design properties. The weight used for estimation was based on the products of the inverse of the probability of sampling, the non-response adjustment factor, and a post-stratification adjustment by age, gender, and ethnicity. Statistical analysis was performed using STATA 14 (Stata Corporation, College Station, TX). 


\section{Results}

A total of 11,308 respondents, estimated to represent 21.7 million adults aged 18 years and over in Malaysia were included in the analysis. Table 1 summarises the sociodemographic characteristics of the respondents. Females made up $50.1 \%$ of the respondents and those aged 18-34 years old were $44.5 \%$ of the respondents. $51.4 \%$ of the respondents were Malay, $88.5 \%$ were Malaysian, and $63.1 \%$ were married. $48.8 \%$ of respondents reported their highest education level to be up to secondary education. Private employees made up $37.7 \%$ of the respondents and $62.1 \%$ were working. About one-third (33.1\%) of the respondents had medical check-up. The $20 \%$ poorest made up $20.8 \%$ of the respondents. Majority of the respondents were from the urban locality (75.4\%) and had self-rated good to excellent health (79.1\%).

Prevalence of oral healthcare utilisation among adults aged 18 years and over in Malaysia in the 12 months preceding the study was $13.2 \%$ (95\% CI $=12.0 \%, 14.5 \%)$. Comparison of characteristics of those who utilised oral healthcare is summarised in Table 2. Those who utilised had similar characteristics except for sex, age, marital status, education level, occupation, utilisation of medical check-up, and household income quintile.

Table 3 displays the results of the logistic regression analysis of oral healthcare utilisation, with crude and adjusted odds ratios, and their confidence intervals and p-values.

\section{Oral healthcare utilisation in the last 12 months}

In the univariate analysis, variables with highly significant association with greater likelihood of using oral healthcare in the last 12 months were sex, age, citizenship, marital status, education level, occupation, utilisation of medical check-up in the last 12 months, and household income quintile $(p<0.001)$. The $p$ value for urbanity was 0.159. All variables were included in the final model of multivariate analysis except ethnicity, working status, and self-rated health status ( $p$ values $>0.25$ in the univariate analysis).

For predisposing factors, after controlling for all other variables in the model, the likelihood for oral healthcare utilisation in the last 12 months were higher among females $(\mathrm{OR}=1.57,95 \% \mathrm{CI}=1.25,1.96)$. Younger adults had higher odds of oral healthcare utilisation compared to elderly aged 60 years and older. Those aged $18-34$ years were 1.64 times more likely to use oral healthcare in the last 12 months compared to those aged 60 years and older. Married population had higher odds of oral healthcare utilisation $(\mathrm{OR}=1.65$, $95 \% \mathrm{CI}=1.23,2.22)$ compared to widow(er)/divorcee. Adults with tertiary education had higher odds of oral
Table 1 Characteristics of respondents $(N=11,308)$

\begin{tabular}{|c|c|c|c|}
\hline Characteristics & $\begin{array}{l}\text { Count, } \mathrm{n} \\
\text { (Unweighted) }\end{array}$ & $\begin{array}{l}\text { Estimated } \\
\text { population, } \\
\mathrm{N} \\
\text { (Weighted) }\end{array}$ & Percentage (\%) \\
\hline \multicolumn{4}{|l|}{ Predisposing factors } \\
\hline \multicolumn{4}{|l|}{ Demographic profile } \\
\hline \multicolumn{4}{|l|}{ Sex } \\
\hline Male & 5345 & $10,808,937$ & 49.9 \\
\hline Female & 5963 & $10,844,610$ & 50.1 \\
\hline \multicolumn{4}{|l|}{ Age group (years) } \\
\hline $18-34$ & 3608 & $9,637,542$ & 44.5 \\
\hline $35-44$ & 2246 & $4,187,976$ & 19.3 \\
\hline $45-59$ & 3025 & $4,625,530$ & 21.4 \\
\hline $60+$ & 2429 & $3,202,499$ & 14.8 \\
\hline \multicolumn{4}{|l|}{ Ethnicity } \\
\hline Malay* & 7409 & $11,122,297$ & 51.4 \\
\hline Chinese & 1429 & $4,630,824$ & 21.4 \\
\hline Indian & 727 & $1,323,426$ & 6.1 \\
\hline Other Bumiputera & 1114 & $2,266,043$ & 10.5 \\
\hline Others & 629 & $2,310,957$ & 10.7 \\
\hline \multicolumn{4}{|l|}{ Citizenship } \\
\hline Malaysian & 10,603 & $19,162,080$ & 88.5 \\
\hline Non-Malaysian & 705 & $2,491,466$ & 11.5 \\
\hline \multicolumn{4}{|l|}{ Marital status } \\
\hline Single & 2397 & $6,277,951$ & 29.0 \\
\hline Married & 7697 & $13,652,757$ & 63.1 \\
\hline Widow(er)/Divorcee & 1214 & $1,722,839$ & 8.0 \\
\hline \multicolumn{4}{|l|}{ Socio-economic status } \\
\hline \multicolumn{4}{|l|}{ Education level } \\
\hline No formal education & 666 & $1,191,602$ & 5.5 \\
\hline Primary education & 2492 & $4,315,337$ & 19.9 \\
\hline $\begin{array}{l}\text { Secondary educa- } \\
\text { tion }\end{array}$ & 5390 & $10,560,355$ & 48.8 \\
\hline Tertiary education & 2760 & $5,586,253$ & 25.8 \\
\hline \multicolumn{4}{|l|}{ Occupation } \\
\hline $\begin{array}{l}\text { Government } \\
\text { employee }\end{array}$ & 1176 & $1,510,221$ & 7.0 \\
\hline Private employee & 3299 & $8,155,526$ & 37.7 \\
\hline Self-employed & 2132 & $3,851,320$ & 17.8 \\
\hline $\begin{array}{l}\text { Unpaid worker/ } \\
\text { Housewife }\end{array}$ & 2064 & $3,705,499$ & 17.1 \\
\hline Retiree & 522 & 735,685 & 3.4 \\
\hline Student & 312 & 863,511 & 4.0 \\
\hline $\begin{array}{l}\text { Not economically } \\
\text { active }^{\dagger}\end{array}$ & 1803 & $2,831,784$ & 13.1 \\
\hline \multicolumn{4}{|l|}{ Working status } \\
\hline Not working & 4742 & $8,213,140$ & 37.9 \\
\hline Working & 6566 & $13,440,407$ & 62.1 \\
\hline \multicolumn{4}{|l|}{ Health belief } \\
\hline \multicolumn{4}{|l|}{ Medical check-up } \\
\hline Yes & 4379 & $7,171,053$ & 33.1 \\
\hline No & 6929 & $14,482,494$ & 66.9 \\
\hline
\end{tabular}


Table 1 (continued)

\begin{tabular}{lll}
\hline Characteristics & Count, $\mathrm{n}$ & Estimated Percentage (\%) \\
& (Unweighted) & population, \\
& $\mathrm{N}$ \\
& & (Weighted)
\end{tabular}

\begin{tabular}{|c|c|c|c|}
\hline \multicolumn{4}{|l|}{ Enabling factors } \\
\hline \multicolumn{4}{|c|}{ Household income quintile } \\
\hline Q1 (20\% poorest) & 2449 & $4,507,679$ & 20.8 \\
\hline Q2 & 2230 & $4,281,591$ & 19.8 \\
\hline Q3 & 2202 & $4,411,873$ & 20.4 \\
\hline Q4 & 2247 & $4,234,963$ & 19.6 \\
\hline Q5 (20\% richest) & 2180 & $4,217,440$ & 19.5 \\
\hline \multicolumn{4}{|l|}{ Urbanity } \\
\hline Urban & 6772 & $16,335,491$ & 75.4 \\
\hline Rural & 4536 & $5,318,055$ & 24.6 \\
\hline \multicolumn{4}{|l|}{ Need factor } \\
\hline \multicolumn{4}{|c|}{ Self-rated health status } \\
\hline $\begin{array}{l}\text { Good to excellent } \\
\text { health }\end{array}$ & 8532 & $17,120,580$ & 79.1 \\
\hline Fair health & 2502 & $4,084,033$ & 18.9 \\
\hline $\begin{array}{l}\text { Poor to very poor } \\
\text { health }\end{array}$ & 274 & 448,933 & 2.1 \\
\hline
\end{tabular}

healthcare utilisation in the last 12 months $(\mathrm{OR}=2.21$, $95 \% \mathrm{CI}=1.23,3.99)$ compared to those with no formal education. Those with medical check-up in the last 12 months had higher odds of oral healthcare utilisation. For enabling factor, the richest 20\% (Q5) were 1.43 times more likely to use oral healthcare compared to the poorest $20 \%$. In the final model, status of citizenship, occupation, and urbanity were not significantly associated with oral healthcare utilisation. The $p$ value for this model was $>0.05$; this model is a good fit.

\section{Discussion}

This study aimed to determine the prevalence of oral healthcare utilisation and used Andersen's Behavioural Model to identify associated factors of oral healthcare utilisation by adults in Malaysia. Oral healthcare utilisation in the last 12 months by adults in Malaysia was $13.2 \%$. Inequalities were observed; females, married individuals, younger adults, those with higher education, those who had medical check-up in the last 12 months, and those with higher income were more likely to utilise oral healthcare.

Oral healthcare utilisation in Malaysia is still low, considering the efforts done by the Ministry of Health Malaysia to encourage participation and utilisation of oral healthcare services. Every year, various oral health promotion activities such as community outreach programmes which offers free oral examination and awareness talk to target groups were conducted by the Ministry of Health Malaysia to increase oral health awareness and encourage oral healthcare utilisation among the public. However, participation is often low [27] which prompts a need for future studies to explore the reasons for the lack of enthusiasm among the public towards programmes conducted by the Ministry of Health Malaysia. Across 27 Organisation for Economic Co-operation and Development (OECD) countries, around $63 \%$ of individuals reported oral healthcare utilisation in the past year [28], which was higher compared to Malaysia. Compared to neighbouring countries like Thailand [range of $6.63 \%$ (aged 60 years and over) $-8.81 \%$ (aged 15-24 years)] [29] and Indonesia [regular users: $1.2 \%$ (aged 15 years and over)] [10], Malaysia fared better in oral healthcare utilisation. However, Malaysia's oral healthcare utilisation was low when compared to middle income countries like Brazil [less than one year since last dental visit: 44.4\% (aged 18 years and over)] [30]. Nonetheless, these data are not directly comparable due to differences in methods and variable measured. Low oral healthcare utilisation may be associated with low perceived need for oral healthcare [31]. In 2010, adults in Malaysia who never sought oral healthcare stated not having any oral healthcare problem as the most common reason for non-utilisation of oral healthcare [3]. In 2015, $73.4 \%$ of the population in Malaysia experienced oral health problem(s) but did not seek oral healthcare, with the majority (46.1\%) practising self-medication [32].

The NOHSA 2010 indicated that $27.4 \%$ of the adult population aged 15 years and above utilised oral healthcare in the past one year, a finding much higher than our study. A possible explanation could be the fact that the NOHSA 2010 was conducted by interviewers who were oral healthcare professionals while our study interview was conducted by research assistants who were not oral healthcare professionals [3]. Study have shown interviewer effect on respondents during data collection in public health surveys which tend to introduce a bias where the respondent reports the desired answer to escape negative consequences or out of fear [33, 34]. The NOHSA 2010 also included respondents aged 15 to 17 years old compared to our study which included only respondents aged 18 years and above [3]. The incremental school oral health programme in Malaysia covers students up to the age of 17 years old, which could explain the higher oral healthcare utilisation rate in NOHSA 2010 compared to our study [8].

Published literature suggests an inverse relationship between regular oral healthcare utilisation and increasing age [35]. In this study, working age adults (18-59 years) were more likely to utilise oral healthcare than the elderly 
Table 2 Characteristics of adults aged 18 years and over who utilised oral healthcare $(\mathbf{N}=1596)$

\begin{tabular}{|c|c|c|c|c|}
\hline Characteristics & Count, $n$ (Unweighted) & $\begin{array}{l}\text { Estimated population, } \mathrm{N} \\
\text { (Weighted) }\end{array}$ & $\begin{array}{l}\text { Prevalence, \% } \\
(95 \% \mathrm{Cl})\end{array}$ & $p$ value \\
\hline Malaysia & 1596 & $2,848,576$ & $13.2(12.0-14.5)$ & - \\
\hline \multicolumn{5}{|l|}{ Predisposing factors } \\
\hline \multicolumn{5}{|l|}{ Demographic profile } \\
\hline \multicolumn{5}{|l|}{ Sex } \\
\hline Male & 574 & $1,136,872$ & $10.5(8.9-12.4)$ & \multirow[t]{2}{*}{$<0.001$} \\
\hline Female & 1022 & $1,711,703$ & $15.8(14.3-17.4)$ & \\
\hline \multicolumn{5}{|l|}{ Age group (years) } \\
\hline $18-34$ & 595 & $1,377,064$ & $14.3(12.3-16.5)$ & \multirow[t]{4}{*}{$<0.001$} \\
\hline $35-44$ & 376 & 571,705 & $13.7(11.7-15.9)$ & \\
\hline $45-59$ & 420 & 637,588 & $13.8(12.0-15.8)$ & \\
\hline $60+$ & 205 & 262,219 & $8.2(6.7-10.0)$ & \\
\hline \multicolumn{5}{|l|}{ Ethnicity } \\
\hline Malay* & 1101 & $1,592,232$ & $14.3(13.0-15.7)$ & \multirow[t]{5}{*}{0.093} \\
\hline Chinese & 172 & 586,266 & $12.7(9.8-16.2)$ & \\
\hline Indian & 109 & 203,961 & $15.4(11.5-20.3)$ & \\
\hline Other Bumiputera & 170 & 313,197 & $13.8(10.9-17.4)$ & \\
\hline Others & 44 & 152,921 & $6.6(2.8-14.7)$ & \\
\hline \multicolumn{5}{|l|}{ Citizenship } \\
\hline Malaysian & 1545 & $2,661,177$ & $13.9(12.7-15.1)$ & \multirow[t]{2}{*}{0.080} \\
\hline Non-Malaysian & 51 & 187,399 & $7.5(3.6-15.0)$ & \\
\hline \multicolumn{5}{|l|}{ Marital status } \\
\hline Single & 346 & 815,440 & $13.0(11.0-15.3)$ & \multirow[t]{3}{*}{0.001} \\
\hline Married & 1138 & $1,906,892$ & $14.0(12.5-15.6)$ & \\
\hline Widow(er)/Divorcee & 112 & 126,244 & $7.3(5.8-9.2)$ & \\
\hline \multicolumn{5}{|l|}{ Socioeconomic status } \\
\hline \multicolumn{5}{|l|}{ Education level } \\
\hline No formal education & 50 & 89,293 & $7.5(5.0-11.1)$ & \multirow[t]{4}{*}{$<0.001$} \\
\hline Primary education & 193 & 282,622 & $6.5(5.2-8.3)$ & \\
\hline Secondary education & 732 & $1,316,176$ & $12.5(10.9-14.2)$ & \\
\hline Tertiary education & 621 & $1,160,485$ & $20.8(18.2-23.6)$ & \\
\hline \multicolumn{5}{|l|}{ Occupation } \\
\hline Government employee & 280 & 326,851 & $21.6(18.2-25.5)$ & \multirow[t]{7}{*}{$<0.001$} \\
\hline Private employee & 453 & $1,046,103$ & $12.8(10.7-15.3)$ & \\
\hline Self-employed & 226 & 395,824 & $10.3(8.4-12.5)$ & \\
\hline Unpaid worker/Housewife & 318 & 528,136 & $14.3(12.3-16.5)$ & \\
\hline Retiree & 80 & 94,921 & $12.9(9.2-17.8)$ & \\
\hline Student & 79 & 181,488 & $21.0(14.7-29.1)$ & \\
\hline Not economically active ${ }^{\dagger}$ & 160 & 275,252 & $9.7(7.7-12.3)$ & \\
\hline \multicolumn{5}{|l|}{ Working status } \\
\hline Not working & 647 & $1,091,949$ & $13.3(11.8-15.0)$ & \multirow[t]{2}{*}{0.826} \\
\hline Working & 949 & $1,756,627$ & $13.1(11.6-14.7)$ & \\
\hline \multicolumn{5}{|l|}{ Health belief } \\
\hline \multicolumn{5}{|l|}{ Medical check-up } \\
\hline Yes & 812 & $1,268,343$ & $17.7(15.9-19.6)$ & \multirow[t]{2}{*}{$<0.001$} \\
\hline No & 784 & $1,580,233$ & $10.9(9.5-12.5)$ & \\
\hline
\end{tabular}

( $\geq 60$ years). Lo et al. [36] found oral healthcare utilisation of preventive purpose in young adults ( 35 to 44 years) and curative purpose in the elderly (65 to 75 years).
Harford et al. [37] indicated a high proportion of adults (25-44 years) going for oral health check-up. Oral Health Care Programme for the Elderly was introduced by the 
Table 2 (continued)

\begin{tabular}{llll}
\hline Characteristics & Count, $\mathbf{n}$ (Unweighted) & $\begin{array}{l}\text { Estimated population, } \\
\text { (Weighted) }\end{array}$ & $\begin{array}{l}\text { Prevalence, \% } \\
\mathbf{( 9 5 \% ~ C l )}\end{array}$ \\
\hline $\begin{array}{l}\text { Enabling factors } \\
\text { Household income quintile }\end{array}$ & & $\boldsymbol{p}$ value \\
Q1 (20\% poorest) & 246 & 467,068 & $10.4(8.6-12.4)$ \\
Q2 & 261 & 464,069 & $10.8(8.3-14.1)$ \\
Q3 & 280 & 464,103 & $10.5(8.8-12.6)$ \\
Q4 & 343 & 597,262 & $14.1(12.1-16.4)$ \\
Q5 (20\% richest) & 466 & 856,073 & $20.3(17.4-23.6)$ \\
Urbanity & & & $13.6(12.1-15.2)$ \\
Urban & 1074 & $2,221,183$ & $11.8(10.0-13.9)$ \\
Rural & 522 & 627,393 & 0.159 \\
Need factor & & & $13.1(11.7-14.6)$ \\
Self-rated health status & & & $13.8(11.8-15.9)$ \\
Good to excellent health & 1190 & $2,234,735$ & $11.6(7.0-18.6)$
\end{tabular}

Ministry of Health Malaysia in 1983 as an initiative to promote oral health among the elderly [38]. Its implementation was confined within residential institutions, while a revised guideline in 2002 included national oral health goals such as domiciliary oral healthcare services, facilities and delivery systems improvement, elderly care training for oral health professionals and caregivers, and multi-sector collaborations to promote oral health for the elderly [38]. Oral healthcare utilisation among the elderly was still low despite the various efforts; $14.7 \%$ of Malaysians aged 60 years and over had never seen a dentist, and $86.1 \%$ did not use oral healthcare during the previous year [3]. Having a problem (65.2\%), completing treatment (18.6\%), and being sent a reminder $(1.5 \%)$ was the main reason for their last oral healthcare utilisation [3]. The same study indicated that less than $10 \%$ of adults in Malaysia reported the need for timely oral healthcare utilisation [3]. Barriers to elderly oral healthcare utilisation were not specifically reported, with around $24.8 \%$ expressing some fear of oral healthcare utilisation [3].

This study showed that higher educated groups utilise oral healthcare services more than the less educated, a finding consistent with other study [13]. Education may be correlated with higher health consciousness which stimulates preventive behaviour such as regular oral healthcare utilisation [39]. According to findings from NHMS 2019, only $29.9 \%$ of population with oral health problems within two weeks prior to the interview perceived the need to seek treatment from a healthcare practitioner [23]. The main reasons for not seeking care from a healthcare practitioner when they had oral health problems were not being sick enough to necessitate treatment, work commitment, and self-medication [23]. These findings indicate that there is still a lack of awareness among the population in Malaysia regarding the importance of prevention in oral health. A national population study in Malaysia conducted in year 2019 showed sufficient health literacy level in only $40.7 \%$ of the population, followed by limited health literacy level in $35.0 \%$ and excellent health literacy level in $24.3 \%$ of the population [40]. However, data from the World Bank in 2018 shows that adults in Malaysia had literacy rate of $94.85 \%$ which is relatively high compared to some neighbouring country such as Thailand which had literacy rate of $93.77 \%$ in the same year [41]. This prompts the need to explore other factors such as local culture, beliefs, and taboos which could have contributed to the lack of awareness on the importance of prevention in oral health, leading to low utilisation of oral health services.

The higher odds of oral healthcare utilisation among population with medical check-up in this study could be attributed to the antenatal programme [8], as antenatal check-up was considered a form of medical check-up in NHMS 2019. Oral health is integral to general health. Having a health condition would necessitate a medical check-up and those with long standing health condition have been associated with higher utilisation of oral healthcare services [42]. Additional knowledge on oral 
Table 3 Logistics regression analysis of oral healthcare utilisation among adults aged 18 years and over

\begin{tabular}{|c|c|c|c|c|}
\hline Variables & Crude OR $(95 \% \mathrm{Cl})$ & $p$ value & Adjusted OR (95\% Cl) & $p$ value \\
\hline \multicolumn{5}{|l|}{ Sex } \\
\hline Female & $1.59(1.29-1.97)$ & $<0.001$ & $1.57(1.25-1.96)$ & $<0.001$ \\
\hline Male & Ref & - & Ref & - \\
\hline \multicolumn{5}{|l|}{ Age group (years) } \\
\hline $18-34$ & $1.87(1.43-2.44)$ & $<0.001$ & $1.64(1.15-2.33)$ & 0.007 \\
\hline $35-44$ & $1.77(1.34-2.35)$ & & $1.42(0.98-2.07)$ & 0.064 \\
\hline $45-59$ & $1.79(1.39-2.32)$ & & $1.44(1.03-2.00)$ & 0.031 \\
\hline $60+$ & Ref & - & Ref & - \\
\hline \multicolumn{5}{|l|}{ Ethnicity } \\
\hline Malay* & $1.15(0.85-1.57)$ & 0.313 & & - \\
\hline Indian & $1.26(0.81-1.94)$ & & & - \\
\hline Other Bumiputera & $1.11(0.73-1.67)$ & & & - \\
\hline Others & $0.49(0.19-1.24)$ & & & - \\
\hline Chinese & $\operatorname{Ref}$ & - & & - \\
\hline \multicolumn{5}{|l|}{ Citizenship } \\
\hline Malaysian & $1.98(0.91-4.33)$ & $<0.001$ & $1.30(0.59-2.88)$ & 0.513 \\
\hline Non-Malaysian & Ref & - & Ref & - \\
\hline \multicolumn{5}{|l|}{ Marital status } \\
\hline Single & $1.89(1.41-2.53)$ & $<0.001$ & $1.33(0.88-2.02)$ & 0.175 \\
\hline Married & $2.05(1.56-2.70)$ & & $1.65(1.23-2.22)$ & 0.001 \\
\hline Widow(er)/Divorcee & Ref & - & Ref & - \\
\hline \multicolumn{5}{|l|}{ Education level } \\
\hline No formal education & Ref & - & Ref & - \\
\hline Primary education & $0.87(0.53-1.40)$ & $<0.001$ & $0.83(0.51-1.38)$ & 0.477 \\
\hline Secondary education & $1.76(1.10-2.80)$ & & $1.42(0.78-2.58)$ & 0.246 \\
\hline Tertiary education & $3.24(2.04-5.14)$ & & $2.21(1.23-3.99)$ & 0.008 \\
\hline \multicolumn{5}{|l|}{ Occupation } \\
\hline Government employee & $2.57(1.83-3.60)$ & $<0.001$ & $1.06(0.72-1.56)$ & 0.774 \\
\hline Private employee & $1.37(0.98-1.90)$ & & $0.96(0.68-1.34)$ & 0.796 \\
\hline Self-employed & $1.06(0.77-1.48)$ & & $0.87(0.60-1.24)$ & 0.439 \\
\hline Unpaid worker/Housewife & $1.54(1.14-2.10)$ & & $0.98(0.70-1.38)$ & 0.922 \\
\hline Retiree & $1.38(0.90-2.10)$ & & $1.14(0.69-1.86)$ & 0.611 \\
\hline Student & $2.47(1.51-4.05)$ & & $1.52(0.88-2.60)$ & 0.130 \\
\hline Not economically active $^{\dagger}$ & Ref & - & Ref & - \\
\hline \multicolumn{5}{|l|}{ Working status } \\
\hline Working & $0.98(0.82-1.17)$ & 0.826 & & - \\
\hline Not working & Ref & - & & - \\
\hline \multicolumn{5}{|l|}{ Medical check-up } \\
\hline Yes & $1.75(1.46-2.11)$ & $<0.001$ & $1.86(1.53-2.25)$ & $<0.001$ \\
\hline No & Ref & - & Ref & - \\
\hline \multicolumn{5}{|l|}{ Household income quintile } \\
\hline Q1 (20\% poorest) & Ref & - & Ref & - \\
\hline Q2 & $1.05(0.74-1.49)$ & $<0.001$ & $1.01(0.72-1.41)$ & 0.963 \\
\hline Q3 & $1.02(0.78-1.33)$ & & $0.86(0.65-1.16)$ & 0.330 \\
\hline Q4 & $1.42(1.11-1.81)$ & & $1.12(0.85-1.46)$ & 0.420 \\
\hline Q5 (20\% richest) & $2.20(1.67-2.91)$ & & $1.43(1.04-1.96)$ & 0.026 \\
\hline \multicolumn{5}{|l|}{ Urbanity } \\
\hline Urban & $1.18(0.94-1.48)$ & 0.159 & $0.96(0.77-1.20)$ & 0.728 \\
\hline Rural & Ref & - & Ref & - \\
\hline
\end{tabular}


Table 3 (continued)

\begin{tabular}{|c|c|c|c|c|}
\hline Variables & Crude OR $(95 \% \mathrm{Cl})$ & $p$ value & Adjusted OR $(95 \% \mathrm{Cl})$ & $p$ value \\
\hline \multicolumn{5}{|l|}{ Self-rated health status } \\
\hline Good to excellent health & $1.15(0.65-2.03)$ & 0.708 & & - \\
\hline Fair health & $1.22(0.69-2.16)$ & & & - \\
\hline Poor to very poor health & Ref & - & & - \\
\hline
\end{tabular}

health among other healthcare groups would ensure patient's oral health needs are addressed and appropriate referral to the dentist is made during routine medical check-up. For instance, individuals with risk factor for oral health problem such as non-communicable diseases and smoking should be referred to the dentist whenever possible [2]. As such, medical, nursing, and allied-health programmes in institutions of higher learning could incorporate inter-professional and multidisciplinary oral health education as part of their curriculum to enable identification of oral health conditions and make appropriate referrals for oral healthcare, in preparation for future healthcare teams to manage people holistically in their general health as well as oral health $[4,43]$.

In our study, the richest income quintile had greater odds of visiting the dentist than the poorest income quintile, in line with the positive effect of income on oral healthcare utilisation [13]. A study among low income Canadians indicated oral healthcare utilisation as a competing financial demand for economically constrained adults [44]. In OECD countries, differences in visits between high and low-income groups were almost $20 \%$ (72\% of wealthier individuals visited a dentist, compared with $54 \%$ among those from the lowest income quintile), indicating large socioeconomic disparities [28]. Low socioeconomic status may be associated with more emotional and physical consequences of seeking care when complications have occurred [45]. In Malaysia, health-related tax relief are available for complete medical examination and medical expenses for serious diseases for self, spouse, child, as well as medical expenses for parents but oral healthcare services are not considered for income tax relief [46]. Income tax relief for oral health examination for self, spouse, or child and oral healthcare expenses for parent(s) could be implemented in a similar way to that of medical healthcare as a way to promote utilisation of oral healthcare services in the country, especially in the private sector for those who can afford it, to reduce congestion in the public sector [4]. Andersen [22] noted that oral healthcare utilisation was more likely explained by predisposing social structure (e.g. education), predisposing health belief, and enabling factors (e.g. income).

The trend of oral healthcare utilisation among the population of all age groups in Malaysia has always been low. Recent studies indicated the prevalence of oral healthcare utilisation ranged from 22.4 to $23.7 \%$ between 2011 and 2019 [23, 32, 47]. Regular oral healthcare utilisation is important to prevent more complicated and costly procedures in the future. Therefore, it is important to improve the rate of oral healthcare utilisation among the population. Inequalities and inequities in oral healthcare services are prevalent worldwide [48-50]. Oral healthcare inequities in low and middle income countries are rooted in access to services and lack of preventative care [51]. Globally, lack of access to oral healthcare remains a major burden to public health. Although oral healthcare in Malaysia is accessible to all, there are still significant inequalities in oral healthcare utilisation, with the higher income population having better conditions to access these services [52]. Barriers in oral healthcare primarily centred on cost, public health prioritisation, and access; both organisational and geographical [53-56]. In Malaysia, studies have indicated dental fear, time constraints, dissatisfaction with the services rendered such as long waiting time and no immediate treatment given by the dentist, and perception of not having any oral health problems as barriers to oral healthcare utilisation [57, 58]. By understanding factors which influence utilisation of oral healthcare, improvement in oral healthcare utilisation could be achieved through appropriate interventions. Oral healthcare inequalities could be reduced through the implementation of effective and appropriate oral health promotion policies such as population-oriented preventive approach and integrated public health policies [59, 60].

Strengthening collaboration between the public and private sectors, non-governmental organisations (NGO), and social welfare groups to deliver oral healthcare outreach services to vulnerable groups such as the elderly could help improve oral healthcare access [4]. 
Enhancement of the existing domiciliary oral healthcare services for the elderly in Malaysia to cater to more individuals who are unable to attend oral healthcare clinics could also help boost utilisation [61]. Campaigns which advocate the importance of and interrelationship between general health and oral health through multisector collaboration and concerted efforts could help improve public awareness and health services utilisation [4]. In Malaysia, collaboration between the Ministry of Health Malaysia and various organisations not limiting to the Institute of Teacher Education, Oral Cancer Research and Coordinating Centre Malaysia and religious bodies were established to provide oral health talks and free oral examination through outreach programmes to the community they collaborate with [62]. Public-private collaboration such as the Alliance for a Cavity-Free Future Programme between the Ministry of Health Malaysia and the dental industry had a vision of achieving a future generation with zero cavity and better oral health [63]. Continuous monitoring and evaluation of existing programmes such as community empowerment programmes are essential for continuity of the programmes and their success in imparting oral healthcare knowledge to the public especially among those with lower levels of education [4]. In Malaysia, monitoring and evaluation of programmes are routinely done to gauge their effectiveness and acceptance, but in many instances there was poor uptake of the activities of the programmes by the community [27], which suggest a need to explore the public's perception on the effectiveness of these approaches as well as barriers which led to the poor response of the programmes in future studies.

Improving the population's social determinants of health could help improve oral healthcare access [59, 64]. In line with the universal health coverage agenda, oral health check-up and basic oral healthcare should be included as part of primary healthcare benefits package to strengthen healthcare financial mechanism [59]. In Malaysia, oral healthcare in the public sector is largely subsidised by the government and accessible to all citizens, yet utilisation is still low. The long waiting time to see the dentist in the public sector due to overcrowding in public facilities may have reduced the motivation of the population from their regular dental check-up [65]. In order to reduce this waiting time, the Ministry of Health Malaysia in year 2009 implemented a key performance indicator (KPI) for patient waiting time [65]. Over the years, Malaysia has seen an increase in the number of dentists in Malaysia, but without an appreciable increase in infrastructure or equipment [66] and this incompatibility between the number of professionals and facilities does not translate into better access to oral health for the public. Further study to understand the reasons for non-utilisation of oral healthcare despite the efforts poured by the Ministry of Health Malaysia to encourage participation is required so that appropriate interventions that cater to the needs of the population could be formulated to boost up oral healthcare utilisation in Malaysia.

This study used a large sample size involving nationwide population which enables generalisation of results across adults in Malaysia. One limitation to consider is that possible explanations for utilisation differences in oral healthcare like need factors (such as perception and attitudes to oral healthcare, and health literacy) [67], community-related factors (such as availability of health personnel and facilities, travelling cost, distance to facility, and waiting time) [68] and social determinants of health (such as social networks, social interactions, and culture) [69] were not captured in this study. Another limitation is that NHMS data is a twelve-month selfrecall data which is subjected to potential recall bias and the possibility of under-reporting [70].

\section{Conclusion}

Our study indicates that demographic and socioeconomic factors are strong determinants of oral healthcare utilisation in Malaysia with age, sex, marital status, education, income, and medical check-up in the last 12 months as the associated factors. Appropriate interventions to strengthen the existing programmes aimed to promote regular and timely oral health check-ups are needed to improve oral healthcare utilisation.

\section{Abbreviations \\ NHMS: National Health and Morbidity Survey; EBs: Enumeration Blocks; LQs: Living Quarters; SD: Secure Digital; NGO: Non-governmental Organisation; NCD: Non-communicable disease; Cl: Confidence Interval; OR: Odds Ratio; OECD: Organisation for Economic Co-operation and Development; NOHSA: National Oral Health Survey of Adults; MREC: Medical Research and Ethics Committee; NMRR: National Medical Research Register; KPI: Key Performance Indicator.}

\section{Acknowledgement}

The authors would like to thank the Director General of Health, Malaysia for his permission to publish this article. We would like to thank all research team members for their contributions for this study. We are thankful for the kind cooperation of all respondents of the survey.

\section{Authors' contributions}

SJ is the principal investigator for NHMS 2019. TYR and TEH contributed to the conception and study design. TYR, ANMH and MHMY were involved in field data collection. TYR, TEH and SJ analysed and interpreted the data. All authors reviewed, edited, read and approved the final version of the manuscript to be published. All authors agreed to be responsible for all aspect of the manuscript and to ensure that questions related to accuracy or integrity of any part of the manuscript are appropriately investigated and resolved. All authors read and approved the final manuscript.

\section{Funding}

This research was funded by the Ministry of Health Malaysia (NMRR-18-308544207). The funding sources had no involvement in study design, study 
conduct, analysis of the results, writing of this manuscript, and the decision to submit this topic for publication.

\section{Availability of data and materials}

To protect the privacy of the participants, the dataset that supports the findings of this article is not publicly available. The data may be requested from the corresponding author on reasonable request upon permission from the Director General of Health, Malaysia.

\section{Ethics approval and consent to participate}

This is a secondary data analysis from the National Health and Morbidity Survey 2019. Throughout the conduct of the study, the tenets of the Declaration of Helsinki were followed. The National Health and Morbidity Survey 2019 conduct was approved by the Medical Research and Ethics Committee (MREC), Ministry of Health Malaysia (NMRR-18-3085-44207). Consents from the respondents were obtained prior to the interviews.

\section{Consent for publication}

Not applicable.

\section{Competing interests}

The authors declare that they have no competing interests.

\section{Author details}

${ }^{1}$ Institute for Health Systems Research, National Institutes of Health, Ministry of Health Malaysia, Blok B2, Kompleks NIH, No. 1, Jalan Setia Murni U13/52, Seksyen U13 Setia Alam, 40170 Shah Alam, Selangor, Malaysia. ${ }^{2}$ Tengkawang Dental Clinic, Terengganu Health Department, Ministry of Health Malaysia, 21700 Hulu Terengganu, Terengganu, Malaysia.

Received: 26 October 2020 Accepted: 28 December 2020 Published online: 19 January 2021

\section{References}

1. Dörfer C, Benz C, Aida J, Campard G. The relationship of oral health with general health and NCDs: a brief review. Int Dent J. 2017;67:14-8.

2. James SL, Abate D, Abate KH, Abay SM, Abbafati C, Abbasi N, et al. Global, regional, and national incidence, prevalence, and years lived with disability for 354 Diseases and Injuries for 195 countries and territories, 1990-2017: a systematic analysis for the Global Burden of Disease Study 2017. Lancet. 2018;392(10159):1789-858

3. Oral Health Division. National Oral Health Survey of Adults 2010 (NOHSA 2010). Ministry of Health Malaysia; 2013.

4. National Research Council. Improving Access to Oral Health Care for Vulnerable and Underserved Populations. Washington, D.C.: National Academies Press; 2011. doi:https://doi.org/10.17226/13116.

5. Thomson WM, Williams SM, Broadbent JM, Poulton R, Locker D. Long-term dental visiting patterns and adult oral health. J Dent Res. 2010;89:307-11.

6. Cotlear D, Nagpal S, Smith O, Tandon A, Cortez R. Going Universal: How 24 Developing Countries are Implementing Universal Health Coverage from the Bottom Up. The World Bank; 2015. doi:https://doi. org/10.1596/978-1-4648-0610-0.

7. World Health Organization GHODR. UHC service coverage index. The World Bank. https://data.worldbank.org/indicator/SH.UHC.SRVS.CV.XD. Accessed 7 Dec 2020

8. Oral Health Division. Oral Healthcare in Malaysia. Ministry of Health Malaysia. 2005. https://www.mah.se/upload/FAKULTETER/OD/Avdel ningar/who/WPRO/Malaysia/data/oral_healthcare_in_malaysia_05.pdf. Accessed 7 Sep 2020

9. Šiljak S, Janković J, Marinković J, Erić M, Janevic T, Janković S. Dental service utilisation among adults in a European developing country: findings from a national health survey. Int Dent J. 2019;69:200-6.

10. Santoso CMA, Bramantoro T, Nguyen MC, Bagoly Z, Nagy A. Factors affecting dental service utilisation in Indonesia: a population-based multilevel analysis. Int J Environ Res Public Health. 2020;17:5282.

11. Herkrath FJ, Vettore MV, Werneck GL. Contextual and individual factors associated with dental services utilisation by Brazilian adults: a multilevel analysis. PLOS ONE. 2018;13:1-17.
12. Rezaei S, Woldemichael A, Zandian H, Homaie Rad E Veisi N Karami MB. Dental health-care service utilisation and its determinants in West Iran: a cross-sectional study. Int Dent J. 2018:68:176-82.

13. Reda SF, Reda SM, Murray Thomson W, Schwendicke F. Inequality in utilization of dental services: a systematic review and meta-analysis. Am J Public Health. 2018;108:e1-7.

14. Lo ECM, Tan HP. Cultural challenges to oral healthcare implementation in elders. Gerodontology. 2014;31:72-6.

15. McGrath C. The use of Traditional Chinese Medicine in managing oral health-Hong Kong: one country, two systems. Int Dent J. 2005;55:302-6.

16. Atun R, Berman P, Hsiao W, Myers E, Wei AY. Malaysia Health Systems Research Volume 1: Contextual Analysis of the Malaysian Health System, March 2016. South Online J Nurs Res. 2016;1:1-175.

17. Dutton D. Financial, organizational and professional factors affecting health care utilization. Soc Sci Med. 1986;23:721-35.

18. Evans RG, Stoddart GL. Producing health, consuming health care. Soc Sci Med. 1990;31:1347-63.

19. Rosenstock IM. Why people use health services. Milbank Q. 2005:83:1-32

20. Grossman M. On the Concept of Health Capital and the Demand for Health. J Polit Econ. 1972:80(2):223-55.

21. Andersen RM. Revisiting the behavioral model and access to medical care: does it matter? J Health Soc Behav. 1995:36:1-10.

22. Andersen RM. National health surveys and the behavioral model of health services use. Med Care. 2008;46:647-53.

23. Institute for Health Systems Research, Institute for Public Health. National Health and Morbidity Survey 2019 (NHMS 2019) Vol. II: Healthcare Demand. Ministry of Health Malaysia. 2020. http://www.ihsr.moh.gov.my/ images/publication_material/NHMS2019/hcd2019_report.pdf. Accessed 7 Sep 2020.

24. Institute for Health Systems Research. Revision of Healthcare Demand Questionnaire for National Health and Morbidity Survey (NHMS) 2019. Ministry of Health Malaysia; 2018.

25. Masconi KL, Matsha TE, Echouffo-Tcheugui JB, Erasmus RT, Kengne AP. Reporting and handling of missing data in predictive research for prevalent undiagnosed type 2 diabetes mellitus: a systematic review. EPMA J. 2015:6:7.

26. Bursac Z, Gauss CH, Williams DK, Hosmer DW. Purposeful selection of variables in logistic regression. Source Code Biol Med. 2008;3:17.

27. Zakaria S, Salleh SM. A Pilot Study on the Effectiveness of CommunityBased Oral Health Promotion Activities in Malaysia. Malays Dent J. 1:13.

28. OECD iLibrary. Health at a Glance 2019: OECD Indicators. OECD. 2019. https://www.oecd-ilibrary.org/social-issues-migration-health/health-at-aglance-2019_4dd50c09-en. Accessed 7 Sep 2020.

29. Namwichaisirikul R, Pudpong N, Panichkriangkrai W. Analysis of dental service utilization and dental public health policy among thai population in a past decade. KDJ. 2018;21:178-88.

30. Herkrath FJ, Vettore MV, Werneck GL. Utilisation of dental services by Brazilian adults in rural and urban areas: a multi-group structural equation analysis using the Andersen behavioural model. BMC Public Health. 2020;20:953.

31. Adunola F, Garcia I, lafolla T, Boroumand S, Silveira ML, Adesanya M, et al. Self-perceived oral health, normative need, and dental services utilization among dentate adults in the United States: National Health and Nutrition Examination Survey (NHANES) 2011-2014. J Public Health Dent. 2019:79:79-90.

32. Institute for Public Health. National Health and Morbidity Survey 2015 (NHMS 2015) Volume III: Healthcare Demand. Ministry of Health Malaysia. 2015. http://www.iku.gov.my/images/IKU/Document/REPORT/NHMS2 015-Volumelll.pdf. Accessed 7 Sep 2020

33. Craig BJ, Engstrom MC. Public Health and Social Desirability in Kazakhstan: Methodological Considerations. Cent Asian J Glob Health. 2016;4. doi:https://doi.org/10.5195/CAJGH.2015.191.

34. Davis RE, Couper MP, Janz NK, Caldwell CH, Resnicow K. Interviewer effects in public health surveys. Health Educ Res. 2010;25:14-26.

35. Ahmad MS, Razak IA, Borromeo GL. Oral health care for the elderly population in malaysia: a review of current status and future direction. Southeast Asian J Trop Med Public Health. 2018;49:516-26.

36. Lo ECM, Lin HC, Wang ZJ, Wong MCM, Schwarz E. Utilization of dental services in Southern China. J Dent Res. 2001:80:1471-4.

37. Harford JE, Ellershaw AC, Spencer AJ, Australian Research Centre for Population Oral Health, Australian Institute of Health and Welfare. Trends 
in access to dental care among Australian adults 1994-2008. Canberra.: Australian Institute of Health and Welfare; 2011.

38. Oral Health Division. Guidelines on oral health care for the elderly in Malaysia. Ministry of Health Malaysia. 2002. https://www.mah.se/upload/ FAKULTETER/OD/Avdelningar/who/WPRO/Malaysia/data/oral_healthcare _for_the_elderly_in_malaysia.pdf. Accessed 7 Sep 2020.

39. Cheema J, Sabbah W. Inequalities in preventive and restorative dental services in England, Wales and Northern Ireland. Br Dent J. 2016:221:235-9.

40. Institute for Public Health. National Health and Morbidity Survey 2019 (NHMS 2019) Vol. I: Non-communicable Diseases. Ministry of Health Malaysia. 2020. http://www.iku.gov.my/images/IKU/Document/REPORT/ NHMS2019/Report_NHMS2019-NCD v2.pdf. Accessed 6 Oct 2020.

41. UNESCO Institute for Statistics. The World Bank. Literacy rate, adult total (\% of people ages 15 and above). https://data.worldbank.org/indicator/ SE.ADT.LITR.ZS. Accessed 6 Oct 2020

42. Wade A, Hobbs M, Green MA. Investigating the relationship between multimorbidity and dental attendance: a cross-sectional study of UK adults. Br Dent J. 2019;226:138-43.

43. Bhagat $\mathrm{V}$, Hoang $\mathrm{H}$, Crocombe LA, Goldberg LR. Incorporating oral health care education in undergraduate nursing curricula - a systematic review. BMC Nurs. 2020;19:66.

44. Muirhead VE, Quiñonez C, Figueiredo R, Locker D. Predictors of dental care utilization among working poor Canadians. Community Dent Oral Epidemiol. 2009;37:199-208.

45. Mafla AC. Illness perceptions amongst individuals with dental caries. Community Dent Health. 2018:35:16-22.

46. Inland Revenue Board of Malaysia. Tax Relief and Rebate. http://lampi ran1.hasil.gov.my/pdf/pdfam/07_2017_2.pdf. Accessed 7 Dec 2020.

47. Institute for Public Health. National Health and Morbidity Survey 2011 (NHMS 2011) Vol. III: Healthcare Demand. Ministry of Health Malaysia. 2012. http://www.ku.gov.my/images/IKU/Document/REPORT/NHMS2 011-Volumelll.pdf. Accessed 7 Sep 2020.

48. Raison $\mathrm{H}$. Interventions to reduce socio-economic inequalities in dental service utilisation - a systematic review. Community Dent Health. 2019::39-45.

49. Raittio E, Kiiskinen U, Helminen S, Aromaa A, Suominen AL. Incomerelated inequality and inequity in the use of dental services in Finland after a major subsidization reform. Community Dent Oral Epidemiol. 2015:43:240-54

50. Yao CS, MacEntee MI. Inequity in oral health care for elderly Canadians: part 2. Causes and ethical considerations. J Can Dent Assoc. 2014:80:e10.

51. Babyar J. Inclusive Oral Healthcare for a better Future Together. J Med Syst. 2020:44:89.

52. Abu Bakar NS, Manual A, Ab HJ. Socioeconomic status affecting inequity of healthcare utilisation in Malaysia. Malays J Med Sci. 2019;26:79-85.

53. Shaefer HL, Miller M. Improving Access to Oral Health Care Services Among Underserved Populations in the U.S.: Is There a Role for Mid-Level Dental Providers? J Health Care Poor Underserved. 2011:22:740-4.

54. Molete MP, Yengopal V, Moorman J. Oral health needs and barriers to accessing care among the elderly in Johannesburg. SADJ J South Afr Dent Assoc Tydskr Van Suid-Afr Tandheelkd Ver. 2014;69(352):354-7.
55. Slack-Smith L, Hearn L, Scrine C, Durey A. Barriers and enablers for oral health care for people affected by mental health disorders. Aust Dent J. 2017:62:6-13.

56. El-Yousfi S, Jones K, White S, Marshman Z. A rapid review of barriers to oral healthcare for people with protected characteristics. Br Dent J. 2020;228:853-8.

57. Saddki N, Yusoff A, Hwang YL. Factors associated with dental visit and barriers to utilisation of oral health care services in a sample of antenatal mothers in Hospital Universiti Sains Malaysia. BMC Public Health. 2010;10:75

58. Abllah Z, Abdul Aziz KH, Jamani NA. Barriers To Utilization Of Oral Health Care Services Among Antenatal Mothers In Kuantan, Pahang. IIUM Med J Malays. 2017;16. doi:https://doi.org/10.31436/imjm.v16i2.1052.

59. Watt RG, Daly B, Allison P, Macpherson LMD, Venturelli R, Listl S, et al. Ending the neglect of global oral health: time for radical action. Lancet. 2019:394:261-72.

60. Moysés SJ. Inequalities in oral health and oral health promotion. Braz Oral Res. 2012;26:86-93.

61. Simons D, Pearson N, Movasaghi Z. Developing dental services for homeless people in East London. Br Dent J. 2012;213(7):E11.

62. Oral Health Programme. Oral Health Programme Annual Report 2018. Ministry of Health Malaysia. 2018. http://ohd.moh.gov.my/images/pdf/ annual_rpt/annual_rpt18.pdf. Accessed 8 Oct 2020.

63. Alliance for a Cavity-Free Future. Chapter Spotlight. Alliance for a CavityFree Future. https://www.acffglobal.org/chapters/chapters-spotlight/. Accessed 7 Oct 2020.

64. Watt R, Sheiham A. Inequalities in oral health: a review of the evidence and recommendations for action. Br Dent J. 1999;187:6-12.

65. Toh LS, Sern CW. Patient waiting time as a key performance indicator at orthodontic specialist clinics in Selangor. Malays J Public Health Med. 2011:11:10.

66. Othman AA, Yusof Z, Saub R. Malaysian government dentists' experience, willingness and barriers in providing domiciliary care for elderly people. Gerodontology. 2014;31:136-44.

67. Baskaradoss JK. Relationship between oral health literacy and oral health status. BMC Oral Health. 2018:18:1-6.

68. Van Doorslaer E, Clarke P, Savage E, Hall J. Horizontal inequities in Australia's mixed public/private health care system. Health Policy. 2008;86:97-108.

69. Harris RV, Pennington A, Whitehead M. Preventive dental visiting: a critical interpretive synthesis of theory explaining how inequalities arise. Community Dent Oral Epidemiol. 2017:45:120-34.

70. Bhandari A, Wagner T. Self-reported utilization of health care services: Improving measurement and accuracy. Med Care Res Rev. 2006.

\section{Publisher's Note}

Springer Nature remains neutral with regard to jurisdictional claims in published maps and institutional affiliations.

Ready to submit your research? Choose BMC and benefit from:

- fast, convenient online submission

- thorough peer review by experienced researchers in your field

- rapid publication on acceptance

- support for research data, including large and complex data types

- gold Open Access which fosters wider collaboration and increased citations

- maximum visibility for your research: over 100M website views per year

At BMC, research is always in progress.

Learn more biomedcentral.com/submissions 